\title{
Disposable cartridge concept for the on-demand synthesis of turbo Grignards, Knochel-Hauser amides, and magnesium alkoxides
}

\author{
Mateo Berton ${ }^{*}$, Kevin Sheehan ${ }^{2}$, Andrea Adamo $^{2}$ and D. Tyler McQuade ${ }^{* 1}$
}

\author{
Full Research Paper \\ Address: \\ ${ }^{1}$ Department of Chemical and Life Sciences Engineering, Virginia \\ Commonwealth University, Biotech Eight, 737 N. 5th St., Box 980100 , \\ Richmond, VA 23219, USA and 2Zaiput Flow Technologies, 300 2nd \\ Avenue, Waltham, MA 02451, USA \\ Email: \\ Mateo Berton* - moberton@vcu.edu; D. Tyler McQuade ${ }^{*}$ - \\ tmcquade@vcu.edu \\ * Corresponding author \\ Keywords: \\ Knochel-Hauser base; lithium chloride; magnesium; on-demand; \\ packed-bed reactors; plug and flow reactor; synthesizer; turbo \\ Grignard reagent \\ Beilstein J. Org. Chem. 2020, 16, 1343-1356. \\ doi:10.3762/bjoc. 16.115 \\ Received: 02 April 2020 \\ Accepted: 25 May 2020 \\ Published: 19 June 2020 \\ Associate Editor: I. Baxendale \\ (C) 2020 Berton et al.; licensee Beilstein-Institut. \\ License and terms: see end of document.
}

Open Access

\begin{abstract}
Magnesium organometallic reagents occupy a central position in organic synthesis. The freshness of these compounds is the key for achieving a high conversion and reproducible results. Common methods for the synthesis of Grignard reagents from metallic magnesium present safety issues and exhibit a batch-to-batch variability. Tubular reactors of solid reagents combined with solutionphase reagents enable the continuous-flow preparation of organomagnesium reagents. The use of stratified packed-bed columns of magnesium metal and lithium chloride for the synthesis of highly concentrated turbo Grignards is reported. A low-cost pod-style synthesizer prototype, which incorporates single-use prepacked perfluorinated cartridges and bags of reagents for the automated on-demand lab-scale synthesis of carbon, nitrogen, and oxygen turbo magnesium bases is presented. This concept will provide access to fresh organomagnesium reagents on a discovery scale and will do so independent from the operator's experience in flow and/or organometallic chemistry.
\end{abstract}

\section{Introduction}

Flow chemistry has facilitated: (1) new applications of highenergy or otherwise unsafe chemistry [1,2], enabled by a controlled/rapid heat removal and generation and the immediate use of unstable species [3,4]; (2) flash chemistry, where rapid mixing can outcompete unimolecular side reactions [5,6]; (3) new chemistry by conducting reactions outside of normal operating pressures and temperatures [7,8]; (4) new opportunities for the realization of automated chemistry, including 
on-demand systems [9-12]. We have recently focused on systems where solid-reagent cartridges are combined with a solution-phase reagent, including: (1) copper(I) oxide to produce $\mathrm{N}$-heterocyclic carbene- $\mathrm{Cu}(\mathrm{I})$ complexes for use as catalysts [13]; (2) proline to perform proline-based catalytic reactions [14]; (3) zinc powder to produce organozinc halides in tandem with Negishi couplings [15]; (4) zinc complexes to produce fluorescent species [16]; (5) sodium borohydride to reduce carbonyls [17]; (6) red phosphorous to produce polyphosphides [18]. Our initial foray into this area was born out of necessity. We wanted to conduct flow reactions that required solids, and packed beds facilitated the use of solids without clogging. More recently, we began to think about this combination for producing air- and water-sensitive reagents immediately prior to use. In particular, we were interested in addressing a dichotomy where discovery-scale (50-100 mL) organometallic reagents are used with uncertain characteristics, as opposed to a large scale where the specs are often defined for all reagents, including organometallics. The hypothesis is that unstable/unsafe reagents can be synthesized and used as needed for this discovery scale instead of purchasing stock solutions that arrive with uncertain properties and require titration to determine the concentrations.

Both commercial and academic flow systems are commonly constructed for experienced flow chemists and are designed to maximize a versatile operation to explore a broad range of chemical transformations [11,19-30]. These systems are designed to achieve a generality of operation, and this comes with an increase in the cost and complexity of the instruments. Our on-demand approach targets the opposite end of the equipment design spectrum; it requires a low-cost systems designed to carry out only a few specific functions in a safe and robust manner. It also demands to be low-cost in order to have any potential for real-world applications. In other words, to achieve the set goals, innovation is needed to reduce the complexity/ expense of (1) pumps; (2) reactors; (3) valves; (4) fittings, and (5) chemical containers. The design presented here is based on a disposable cartridge concept, inspired by pod-based coffee machines (Figure 1). We took inspiration from recent efforts that demonstrated that simple machines can do valuable chemistry [12]. Our "cartridge" encompasses reagent bags, tubing, and packed-bed columns of solid reagents and product receptacle. These components are deployed in a low-cost machine with a design amenable for the automated lab-scale generation of organomagnesium reagents on demand (Figure 1).

Organomagnesium compounds are omnipresent reagents that serve as nucleophiles and bases. Grignard reagents react with oxygen and water, yielding flammable gases and must be prepared, stored, and handled under an anhydrous inert atmo-

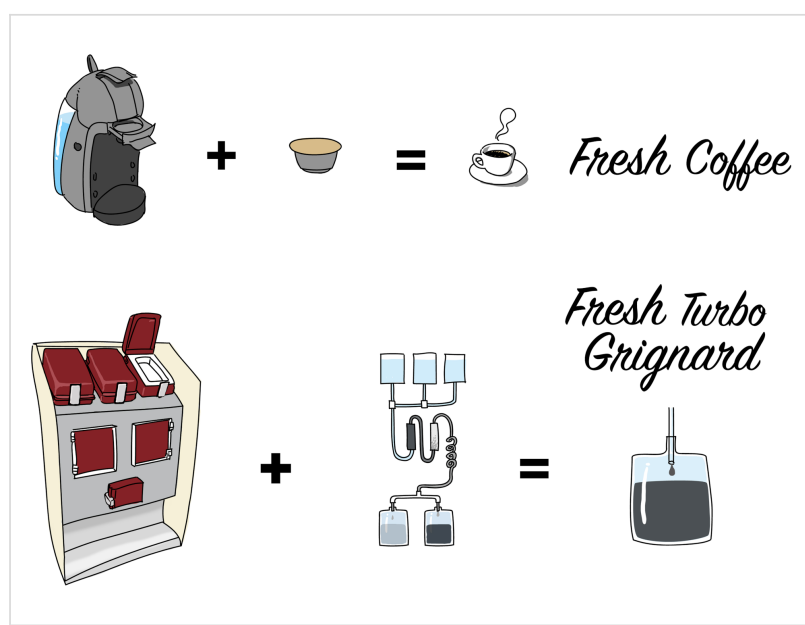

Figure 1: Comparing on-demand coffee and turbo Grignard pod-style machines.

sphere. Time-consuming titration is recommended but is unreliable as only the basicity is estimated. The freshness of these solutions is a key for achieving high conversion because the neutralization can alter the aggregation states, producing a significant batch-to-batch variability. The direct insertion of magnesium metal into organic halides is the most common method used to prepare Grignard reagents but present difficulties: (1) sluggish reactions with ordinary magnesium turnings [31]; (2) the formation of undesired side products by thermal decomposition and exothermic reactions not suitable for industrial processes [32]; (3) the activation of a metallic surface is required and can introduce safety issues due to the high reactivity of the activated metal.

Flow chemistry technologies and cartridges containing activated metals can solve most of these issues: (1) the use of activated magnesium powder packed in a column increases the reaction rate and facilitates safe separation of the metal and reagent solution; (2) an efficient heat transfer (a large surface area-to-volume ratio) provides thermal control during metal activation and the generation of concentrated organometallic solutions; (3) the control over the residence time reduces side products because the organometallic solution is not exposed to high temperatures longer than necessary. All these advantages allow a more straightforward production and use of these critical reagents.

The preparation of organozinc species using zinc packed-bed columns [15,33-35] provides examples for the progression toward the on-demand synthesis of other organometallic reagents. While the concept of a reactive packed bed is not new, many features must be considered and solved for success, including: (1) the column packing-making sure the particle size range and how the column is packed provides a system with 
minimal channeling; (2) selecting a column with the right properties, such as the materials of construction, pressure tolerance, heat conduction, and diameter/particle size matching; (3) the column orientation and setup-filters, etc.; (4) activation of the solid phase. The activation issue is one of the most important factors when considering the metal packing. Although our team had success with zinc packing, we still need to develop a new approach for magnesium. Magnesium, when activated, is more reactive compared to zinc, in part because magnesium is a stronger reducing agent than zinc. Beyond the considerations of the packing, column, and activation, the solubility of organomagnesium reagents is often lower than of the corresponding zincates. The low solubility can clog the column or may reduce the insertion rate by forming a passivating layer over the metal particle surface.

Few examples describe the production of organomagnesium species under flow conditions [36-39], and only three use a practical system with a broad range of substrates [40-42]. The Alcázar group reported the generation and subsequent use of Grignard reagents [40]. In 2018, the Loren group extended the scope of the organozinc reagents made in flow to aryl and tertiary alkyl halides by the in situ formation of the corresponding Grignard intermediate in the presence of $\mathrm{ZnCl}_{2}$ and $\mathrm{LiCl}$, which were subsequently used in Negishi cross-coupling reactions [41]. The most recent example, by the Löb group, reported a pilot plant reactor including a $\mathrm{Mg}$ replenish unit that allowed to generate phenylmagnesium bromide $(1 \mathrm{M})$ at flow rates up to $15 \mathrm{~L} / \mathrm{h}[42]$.

However, in these publications, alkyl chloride substrates, which are generally more cost-effective but less reactive than the cor- responding bromide or iodide, are limited. Also, the use of a $\mathrm{LiCl}$ solution as the reaction medium to increase the Grignard reagent solubility was prepared from hygroscopic $\mathrm{LiCl}$, which implies thorough drying and storage under a moisture-free atmosphere. Finally, the concentration of the Grignard reagents was limited, being in the range of $0.3-0.5 \mathrm{M}$, thereby limiting the range of reaction conditions for the discovery chemist. In this study, we started selecting some of the most used organomagnesium halides in synthesis. For this purpose, a ranking of the 20 most cited ones, as measured by the citation values obtained from SciFinder, was constructed (Figure 2). Based on our analysis, methyl, ethyl, isopropyl, butyl, benzyl, and phenyl as the residue $\mathrm{R}$ were selected as test cases for our proposed system.

Over the last two decades, Knochel demonstrated the benefits of $\mathrm{LiCl}$ on the halogen-magnesium exchange rates [43] and on the organomagnesium solubility [44]. The most known example of this class is the isopropylmagnesium chloride-lithium chloride complex (iPrMgCl-LiCl), known as turbo Grignard [45]. In addition to being widely cited, turbo Grignard is a popular discovery-scale tool in the pharmaceutical industry [32] and has shown an excellent selectivity on a large scale [46]. Halomagnesium amide $\mathrm{LiCl}$ adducts, e.g., the Knochel-Hauser base (TMPMgCl$\cdot \mathrm{LiCl}$ ), are also useful reagents for selective deprotonations due to their strong basicity and low nucleophilicity [47,48]. Knochel-type alkoxides [49], e.g., the 2-methyl-2propoxymagnesium chloride-lithium chloride complex (tertAmylOMgCl$\cdot \mathrm{LiCl}$ ), are less common in synthesis, but their high reactivity and solubility, combined with a high tolerance towards functional groups, made them advantageous for selective transformations.

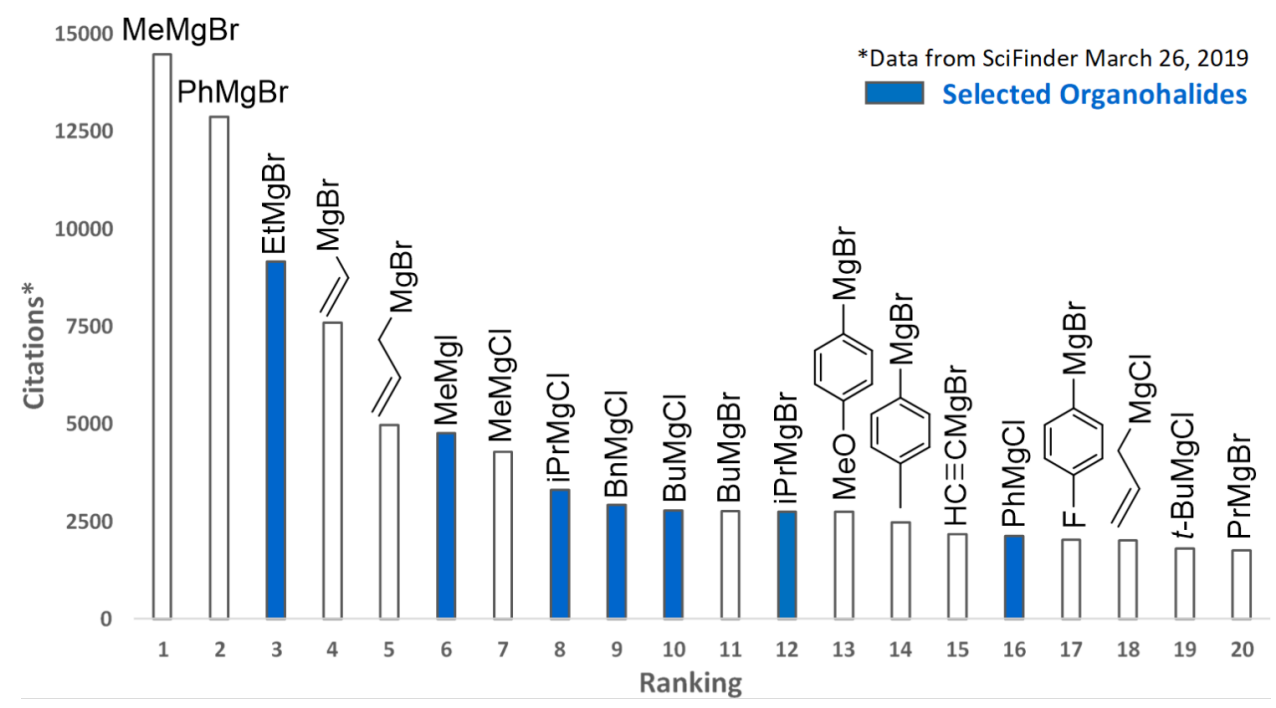

Figure 2: Ranking of the 20 most cited Grignard reagents (SciFinder March 26, 2019). 
Herein, a novel disposable cartridge approach for the on-demand, discovery-scale preparation of turbo Grignard reagents, Knochel-Hauser bases, and new Knochel-type alkoxides using a stratified bicomponent packed-bed column of magnesium and lithium chloride is presented. Critical insights, such as column packing, particle size, metal excess, reagent scope, order of addition, column stability, reproducibility, and consideration of solid/liquid reaction models are presented. In addition, a proof-of-concept, automated pod-type synthesizer prototype designed to generate up to $100 \mathrm{mmol}$ of fresh reagents on demand is described. Our objective is to help others integrate this approach into their quotidian workflow to enable discovery-scale researchers to increase the reliability of their developed routes and processes by increasing the quality of their organomagnesium reagents.

\section{Results and Discussion \\ 1 On-demand reagent prototype}

Objective: To design and create a simple, robust, disposable, and low-cost system capable of producing on-demand reagents for lab-scale purposes using a combination of liquid and solid pods or cartridges. We envisioned a system that requires: (1) pumps; (2) tubular reactors; (3) valves; (4) fittings, and (5) chemical containers.

Challenges: The need to develop new design concepts to achieve (1) low-cost high-pressure pumps (10 bar); (2) disposable tubular reactors; (3) robust valves; (4) leakproof bonding process, and (5) chemically compatible and high-pressure containers.

System design: The pod-style concept is achieved by making the entire fluidic circuit that is needed to run a specific chemistry with prearranged, custom-made, and thermally bonded parts. Parts were built of fully perfluorinated materials, providing an excellent chemical resistance. We chose thermal bonding because this type of bond can provide a leakproof system without the need of fittings. All the fluidic items and reagents assembled together represent the "cartridge" (Figure 3E). Prebuilt disposal cartridges have a long shelf life and can be deployed on demand. The instrument we produced provides the necessary pumping (Figure 3A), heating (Figure 3C), and valving (Figure 3B), which are united in an enclosed unit that can be loaded with self-contained cartridges (Figure 3E). In order to build the disposable cartridges, we developed bonding protocols to carry out the different types of connections needed (i.e., tube to tube, tube to cartridge, tube to bag, tee, etc.).

Pump concept: The pumping is achieved by developing flexible reservoirs made with perfluorinated polymer film (PFA), and the bags are filled with the fluid to dispense. The pumping

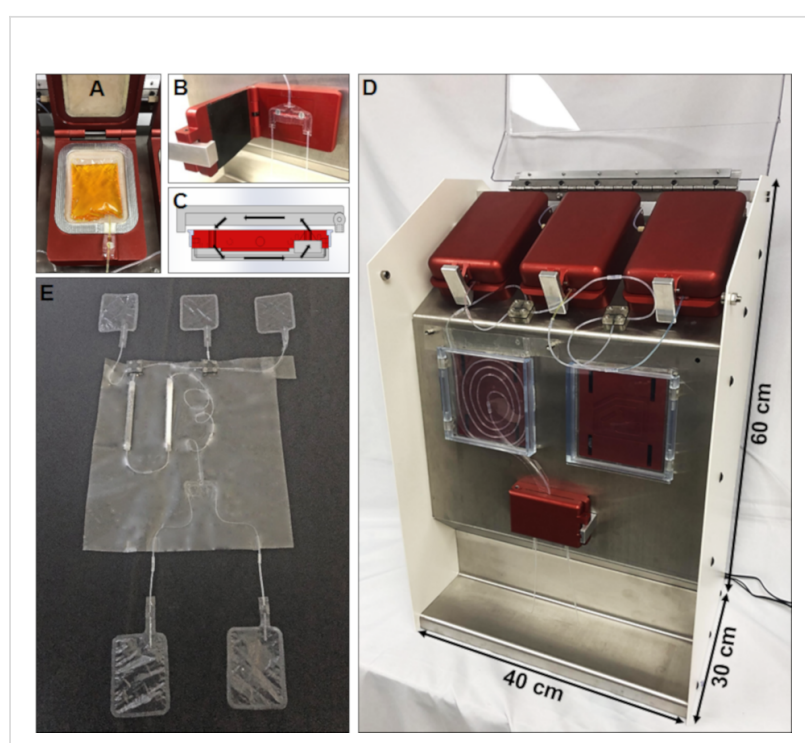

Figure 3: On-demand prototype. A) Inside view of the pump with a flexible bag containing a yellow liquid laying on an elastomer membrane. B) Detail of the manifold used to select the waste or product collection. C) Heater cross section, the arrows indicate the air convection flow path. D) Reagents on-demand system assembled, with the coil reactor placed in the left reactor area. E) Example of a disposable cartridge.

is accomplished by enclosing the bag in a metal clamshell, with contact surfaces made with an elastomer (Figure 3A). When compressed air is pumped in the clamshell, it squeezes the bag through the elastomer, and thus dispensing fluid. The elastomer sheets fully embrace the reagent bag, providing mechanical support. In this way, a soft polymer bag can be squeezed at a relatively high pressure: our prototype achieved pumping pressures up to about $1 \mathrm{MPa}$ (10 bar). This type of pressure-driven pump, where the dispensed liquid is enclosed in a plastic reservoir, provides the advantage of not dissolving any gas into the liquid during the operation, which is the case for pressurized tanks. Additionally, all the wetted parts of the pump are fully disposable (Figure 3E). The metering function required to keep the back pressure and a constant flow rate is achieved by the tubing length and diameter downstream of the pump or by the fluidic network for more complex cases. The flow is pulseless as a result of the fact that it is driven by compressed air.

On-demand reagent (ODR) system design: The ODR prototype (Figure 3D) is essentially composed of three clamshell pumps in order to have up to three process fluids. Each bag contains a valving, so that only specified fluids can be dispensed when required by the process. The instrument offers up to two reaction areas made by aluminum plates. The convection of air is generated with small fans embedded in the aluminum plate to improve the quality of the heat transfer to the reactor. A manifold (Figure $3 \mathrm{~B}$ ) is placed downstream of the 
reaction areas where actuators control the direction of the outcome stream. The solvent priming and the activation solution are discarded into the waste, and only when product is generated, the manifold starts to collect. The system's heating, temperature control, and valving are controlled by an Arduino card (not shown-on the back of the system). Different control routines can be loaded into the Arduino card as needed.

\section{Grignard reagents via magnesium-packed beds}

Objective: To generate concentrated organomagnesium solutions from alkyl halides using a standardized and reproducible packed bed of magnesium, to develop a consistent activation protocol using a single activation solution, and to optimize the conditions for the quantitative organic chloride conversion.

Challenges: Metal surface activation, organomagnesium solubility, formation of a black side product, performance, and degradation over time.

System setup: A commercial flow chemistry system [50] equipped with a temperature-controlled glass manifold reactor [51] was used (Figure S1, Supporting Information File 1). We have found that both glass and PFA columns with similar dimensions can be used. To reduce the costs, the flow chemistry system can be replaced by syringe or HPLC pumps, and the reactor heating can be accomplished using standard heating tools (water/oil bath, heating jacket, or a suitable oven). The 10 $\times 100 \mathrm{~mm}(\mathrm{ID} \times$ length) column was filled with magnesium. A back-pressure regulator (BPR) was added to prevent the gas/ liquid separation and to increase the solvent boiling temperature.
We started reproducing Alcázar's conditions to obtain organomagnesium bromide reagents from the corresponding alkylbromides. The activation protocol was slightly modified: a single activating solution composed of 1-bromo-2-chloroethane, TMSCl, and DIBAL-H in THF/toluene was pumped through magnesium powder $(98 \%, 20-230 \mathrm{mesh})$ at $1 \mathrm{~mL} / \mathrm{min}$ and $40{ }^{\circ} \mathrm{C}$ (Section 1.2.2 in Supporting Information File 1). Organomagnesium bromide reagents $(15 \mathrm{~mL})$ were generated in THF at a $0.5 \mathrm{~mL} / \mathrm{min}$ flow rate and $25^{\circ} \mathrm{C}$. For each experiment, the concentration was determined in duplicates by the reaction with a known mass of two different indicators until a color change occurred: 2-hydroxybenzaldehyde phenylhydrazone [52] or a mixture of benzoic acid and 4-(phenylazo)diphenylamine [53]. Iodine can also be used [54]. Similar concentrations were obtained by NMR titration with 1,5-cyclooctadiene as a standard (Section 1.2.10 in Supporting Information File 1) [55].

The heat released from the exothermic Grignard reaction done at $25^{\circ} \mathrm{C}$ was not fully dissipated by the heat exchanger $\left(\approx 10^{\circ} \mathrm{C}\right.$ increment). To better understand this exothermic process, we decided to measure the temperature evolution during the conversion of $\operatorname{EtBr}(0.5 \mathrm{M})$ at a $0.5 \mathrm{~mL} / \mathrm{min}$ flow rate with no heat controller. Three thermocouples were placed at different points along the glass column (Figure 4 right). The results showed $\mathrm{a} \approx 35{ }^{\circ} \mathrm{C}$ increment, which is an underestimation because the measurements were taken on the outer surface of the glass column. The data featured a hot spot moving upward during the reaction (Figure 4 left), suggesting that magnesium was consumed by the layers at a $0.5 \mathrm{~mL} / \mathrm{min}$ flow rate, and the reaction occurred almost exclusively at the interphase $\mathrm{EtBr}-\mathrm{Mg} *$ and not along the whole column. Since the reactive interphase moved upward at the same rate that $\mathrm{Mg}$ was getting

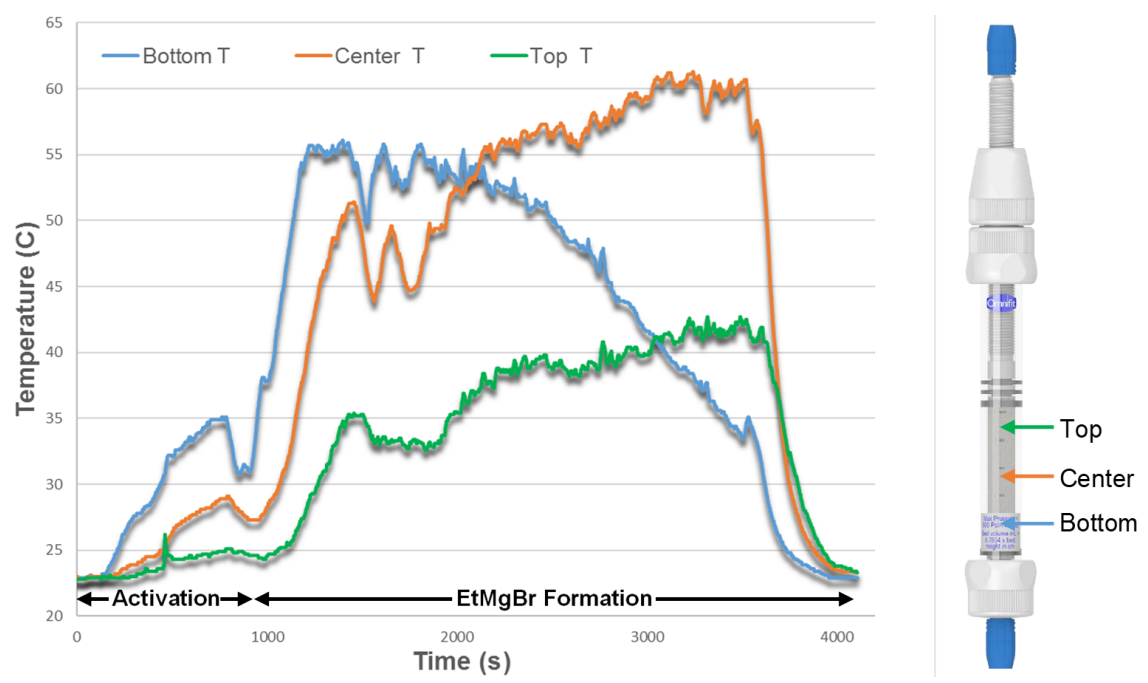

Figure 4: Temperature evolution measured with thermocouples along the column outer surface at three different points. 
consumed, the heat release was not constant along the column, and a steady-state temperature only occurred during a short amount of time at a localized area. The temperature gradient was not observed at higher temperatures $\left(60-100^{\circ} \mathrm{C}\right)$, and the hot spot generated was less than $+5{ }^{\circ} \mathrm{C}$ under these conditions.

During the isopropylmagnesium bromide optimization (Table S4, Supporting Information File 1), solubility issues hindered the formation of a concentrated solution $(>0.8 \mathrm{M})$. The crystallization of $\mathrm{iPrMgBr}$ in the collection flask forced us to reduce the initial concentration of the organic halide to $0.9 \mathrm{M}$, yielding iPrMgBr $(0.75 \mathrm{M}, 82 \%$, note: the yields reported herein refer to the amount of organometallic reagent produced in a steady state; no detectable halide was recovered, and the organometallic reagent purity was high unless otherwise stated, Table S4, entry 3, Supporting Information File 1). The reactivity order of organic halides against oxidative addition reactions is $\mathrm{R}-\mathrm{I}>$ $\mathrm{R}-\mathrm{Br}>\mathrm{R}-\mathrm{Cl}$. To achieve the direct insertion of 2-chloropropane, the temperature was increased, and the best result was obtained at $80{ }^{\circ} \mathrm{C}$, yielding iPrMgCl $(0.78 \mathrm{M}, 87 \%$, Table S4, entry 7 , Supporting Information File 1). Since $\mathrm{PrMgCl}$ is more soluble in THF than the corresponding bromide [56], we were able to use an initial concentration of up to $2.5 \mathrm{M}$, yielding iPrMgCl (2.23 M, 89\%, Table S4, entry 8, Supporting Information File 1). At a temperature higher than $60{ }^{\circ} \mathrm{C}, 100$ psi BPR were required to prevent the solvent from boiling inside the packed-bed column.

During preliminary experiments, we observed the formation of a black residue that was left after the magnesium consumption. While the residue did not affect the column performance for the conversion of $10 \mathrm{~mL}$ of an $\mathrm{irCl}(2.5 \mathrm{M})$ solution, larger generated volumes increased the pressure drop and eventually led to clogging of the system. The analysis of the black residue via X-ray photoelectron spectroscopy (Figure S6, Supporting Information File 1) revealed the presence of magnesium, oxygen, carbon, and chlorine. Although we do not understand the mechanism, we sought a solution that would enable the column performance to remain constant. During the optimization, we tested Mg chips (99.98\%, 6-35 mesh) and observed less black residue. Thus, we explored the reaction using different ratios of $\mathrm{Mg}$ chips/powder (Figure S7, Supporting Information File 1). We found that a $\mathrm{Mg}$ chip/powder ratio of 1:1 provided more consistent results over a relatively large amount $(\approx 100 \mathrm{mmol})$ of organic halide that was converted. We offer two explanations: (1) the higher purity of $\mathrm{Mg}$ chips (99.98\%) and (2) the higher surface area $(\mathrm{SA})$ of the $\mathrm{Mg}$ powder $(\approx 130$ mesh, SA $\approx$ $30 \mathrm{~cm}^{2} / \mathrm{g}$ ) than $\mathrm{Mg}$ chips $\left(\approx 20\right.$ mesh, $\left.\mathrm{SA} \approx 4 \mathrm{~cm}^{2} / \mathrm{g}\right)$. We hypothesize that these features provided a large activated $\mathrm{Mg}$ surface for an initial quantitative conversion and a purer but less reactive material that generated less side products, resulting in an $\mathrm{iPrMgCl}$ yield of up to $97 \%$. The optimal amount of $\mathrm{Mg}$ was determined to be 2 equivalents. The yield drop after the consumption of 1 equiv of $\mathrm{Mg}$ was first attributed to a channeling through the packed bed. To test this hypothesis, we followed the changes in the column using a $4 \mathrm{~K}$ webcam for two types of columns: (1) a firmly packed column and (2) a loosely packed column. The well-packed $\mathrm{Mg}$ column did not consume all the Mg due to the channeling (Figure S8A, Supporting Information File 1), as we proposed. The loosely packed column, to our surprise, behaved like a fluidized bed, allowing $\mathrm{iPrCl}$ to be in contact with a larger surface of $\mathrm{Mg}$ (Figure S8B, Supporting Information File 1) and provide a better performance than a well-packed column: $98 \%$.

System scope: Next, we probed the limit of this transformation for primary (bromoethane, bromooctane, chlorobutane, and iodomethane) and secondary (2-bromopropane, 2-chloropropane, and 2-chlorobutane) alkyl halides as well as benzyl (chloromethylbenzene) and aryl chlorides (chlorobenzene).

Good to excellent yields were obtained (Table 1). In general, bromo-Grignard reagents tend to be less soluble in THF than chloro-Grignard reagents, and other ethereal solvents can be more appropriate: 2-methyltetrahydrofuran (2-MeTHF) or $\mathrm{Et}_{2} \mathrm{O}$. The higher solubility of $\mathrm{EtMgBr}$ in these solvents allowed us to obtain $2.21 \mathrm{M}(88 \%)$ in 2-MeTHF and $2.40 \mathrm{M}(96 \%)$ in $\mathrm{Et}_{2} \mathrm{O}$ but only $1.08 \mathrm{M}(90 \%)$ in THF (Table 1, entries 2-4). The concentration of $\mathrm{n}-\mathrm{Oct} \mathrm{MgBr}$ was also limited to $0.51 \mathrm{M}(85 \%)$ in THF (Table 1, entry 5). The use of $\mathrm{Et}_{2} \mathrm{O}$ increased the solubility up to $1.08 \mathrm{M}(90 \%$, Table 1 , entry 6$)$. Even chlorobenzene, considered a deactivated species, was converted to $\mathrm{PhMgCl}$ in an excellent yield (2.32 M, 93\%, Table 1, entry 10), heating the column to $100{ }^{\circ} \mathrm{C}$. For benzyl chloride, a 2-MeTHF/ THF, 9:1 mixture [57] was found to be optimal to reduce the formation of a Wurtz-type side product, 1,2-diphenylethane (Table S5, Supporting Information File 1), yielding $\mathrm{BnMgCl}$ (0.99 M, 83\%, Table 1, entry 11). Noteworthy, a iodomethane (bp $42{ }^{\circ} \mathrm{C}$ ) solution in $\mathrm{Et}_{2} \mathrm{O}$ can be converted to the corresponding MeMgI in good yield and with a good mass balance using a 140 psi BPR (Table 1, entry 12).

\section{Turbo Grignards via stratified packed-bed columns containing magnesium and $\mathrm{LiCl}$}

Objective: To generate organomagnesium-lithium chloride complexes (turbo Grignards) from alkyl chlorides using a stratified bicomponent packed-bed column composed of magnesium metal and lithium chloride.

Challenges: Metal passivation by lithium chloride coating, handling of $\mathrm{LiCl}$ (hygroscopic), $\mathrm{LiCl}$ equivalent optimization due to the solubilization over time. 
Table 1: Reaction of organic halides in a packed-bed column of activated magnesium. Scope of Grignard reagents prepared under flow conditions. $^{\mathrm{a}}$

\begin{tabular}{|c|c|c|c|c|c|c|}
\hline entry & $\mathrm{RX}$ & $\begin{array}{l}T \\
\left({ }^{\circ} \mathrm{C}\right)\end{array}$ & solvent & $\begin{array}{l}{[\mathrm{RX}]} \\
(\mathrm{M})^{\mathrm{b}}\end{array}$ & $\begin{array}{l}{[\mathrm{RMgX}]} \\
\text { (M) }\end{array}$ & $\begin{array}{l}\text { yield } \\
(\%)^{c}\end{array}$ \\
\hline 1 & $\mathrm{iPrBr}$ & 25 & THF & 0.9 & 0.74 & $82^{d}$ \\
\hline 2 & $\mathrm{EtBr}$ & 25 & THF & 1.2 & 1.08 & 90 \\
\hline 3 & $\mathrm{EtBr}$ & 25 & 2-Me-THF & 2.5 & 2.21 & 88 \\
\hline 4 & $\mathrm{EtBr}$ & 25 & $\mathrm{Et}_{2} \mathrm{O}$ & 2.5 & 2.39 & 96 \\
\hline 5 & $n$-OctBr & 25 & THF & 0.6 & 0.51 & 85 \\
\hline 6 & $n-\mathrm{OctBr}$ & 25 & $\mathrm{Et}_{2} \mathrm{O}$ & 1.2 & 1.08 & 90 \\
\hline 7 & $\mathrm{iPrCl}$ & 80 & THF & 2.5 & 2.38 & 95 \\
\hline 8 & sec-BuCl & 80 & THF & 2.5 & 2.23 & 89 \\
\hline 9 & $n-\mathrm{BuCl}$ & 80 & THF & 2.5 & 2.37 & 95 \\
\hline 10 & $\mathrm{PhCl}$ & 100 & THF & 2.5 & 2.32 & 93 \\
\hline 11 & $\mathrm{BnCl}$ & 60 & 2-Me-THF & 1.2 & 0.99 & $83^{f}$ \\
\hline $12^{g}$ & Mel & 25 & $\mathrm{Et}_{2} \mathrm{O}$ & 2.5 & 2.36 & 94 \\
\hline
\end{tabular}

aThe $\mathrm{RX}$ solution $(20 \mathrm{~mL}$ ) was pumped at a $0.5 \mathrm{~mL} / \mathrm{min}$ flow rate through a column (ID $=10 \mathrm{~mm}$ ) of $\mathrm{Mg}^{*}$ (2 equiv) chips/powder (1:1). ${ }^{\mathrm{b}}$ Quantitative $\mathrm{RX}$ conversion. 'Determined by the titration of an overall $\mathrm{RMgX}$ solution $\left(\approx 15 \mathrm{~mL}\right.$ ) collected at steady state. ${ }^{\mathrm{d}} 2$-Methylpropene obtained as a major side product. ${ }^{\mathrm{e}} 10 \%$ of THF. ${ }^{\mathrm{f}} 1,2$-Diphenylethane was obtained as a single side product. ${ }^{\mathrm{g}} 140 \mathrm{psi}$ BPR.

System setup: The same flow system was used as for the generation of Grignard reagents (Figure S2, Supporting Information File 1). The $10 \times 100 \mathrm{~mm}(\mathrm{ID} \times$ length) column was half filled with magnesium (chips/powder, 1:1) and the second half with anhydrous lithium chloride (Figure 5). The two components were separated by fiberglass previously dried at $120^{\circ} \mathrm{C}$ overnight. A 100 psi BPR was added to prevent the gas/liquid separation and to increase the solvent boiling temperature.

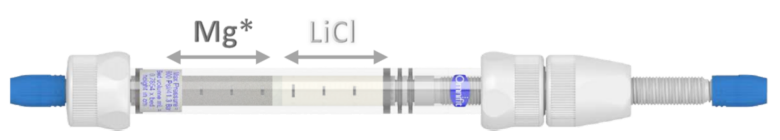

Figure 5: Stratified bicomponent column (Diba Omnifit EZ Solvent Plus) composed of magnesium (chips/powder, 1:1) and lithium chloride separated with fiberglass for the turbo Grignard reagent synthesis.

Clogging is a common concern in flow chemistry, and during our scope exploration, we observed that the concentrations of the organomagnesium reagents generated were mostly limited by their solubility. Knochel pioneered the use of lithium chloride to solubilize organometallic reagents and to increase the reactivity, most probably due to the disaggregation of oligomers $[43,44]$. We used this approach to overcome the solubility issue under continuous conditions. First, we verified that similar results are achieved in presence and absence of $\mathrm{LiCl}$ in solution for the EtMgBr formation (Section 2.2, Supporting Information File 1). Because organomagnesium halide-lithium chloride complexes are believed to be $1: 1 \mathrm{RMgX} \cdot \mathrm{LiCl}$ dimers, and considering the $\mathrm{LiCl}$ solubility limitation of $\approx 0.5 \mathrm{M}$ in THF, we decided to design a new system for the generation of highly concentrated turbo Grignard reagents. Instead of using a solution of starting material and $\mathrm{LiCl}$, a bicomponent packed-bed column was assembled. First, $\approx 4.5 \mathrm{~cm}$ of the Omnifit column was filled with magnesium (chips/powder, 1:1) and the upper $\approx 4.5 \mathrm{~cm}$ with anhydrous lithium chloride (Figure 5). The two components were separated by fiberglass previously dried at $120^{\circ} \mathrm{C}$ overnight. We first tested this column with a $1.5 \mathrm{M} \mathrm{EtBr}$ solution, and a comparable $\mathrm{EtMgBr} \cdot \mathrm{LiCl}$ concentration was obtained (1.30 M, $87 \%$, Table 2, entry 1$)$ in comparison to dissolved $\mathrm{LiCl}$ (1.27 M, 86\%, Table S6, entry 6, Supporting Information File 1).

Table 2: Reaction of organic halides with a stratified packed-bed column of activated magnesium and lithium chloride. Scope of turbo Grignard reagents prepared under flow conditions. ${ }^{\text {a }}$

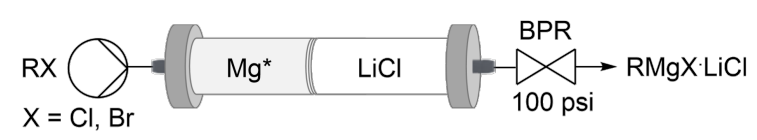

\begin{tabular}{llllll}
\hline entry & $\mathrm{RX}$ & $\begin{array}{l}T \\
\left({ }^{\circ} \mathrm{C}\right)\end{array}$ & {$[\mathrm{RX}](\mathrm{M})^{\mathrm{b}}$} & $\begin{array}{l}{[\mathrm{RMgX} \cdot \mathrm{LiCl}]} \\
(\mathrm{M})\end{array}$ & $\begin{array}{l}\text { yield } \\
(\%)^{\mathrm{c}}\end{array}$ \\
\hline 1 & $\mathrm{EtBr}$ & 25 & 1.5 & 1.30 & 87 \\
2 & $\mathrm{iPrCl}$ & 80 & 2.5 & 2.19 & 88 \\
3 & sec-BuCl & 80 & 2.5 & 2.15 & 86 \\
4 & $n-\mathrm{BuCl}$ & 80 & 2.5 & 2.13 & 85 \\
\hline
\end{tabular}

aThe RX solution ( $15 \mathrm{~mL}$ ) in THF was pumped at a $0.5 \mathrm{~mL} / \mathrm{min}$ flow rate through a bicomponent column (ID $=10 \mathrm{~mm}$ ) composed of activated $\mathrm{Mg}^{*}$ (2 equiv) chips/powder (1:1) and anhydrous $\mathrm{LiCl}$ (2 equiv) separated by fiberglass. ${ }^{b} Q$ uantitative $\mathrm{RX}$ conversion. ${ }^{\mathrm{C}}$ Determined by the titration of the overall $\mathrm{RMgX} \cdot \mathrm{LiCl}$ solution $(\approx 10 \mathrm{~mL})$ collected at steady state.

The separation of the two components was crucial to obtain reproducible results. When $\mathrm{Mg}$ and $\mathrm{LiCl}$ were intimately mixed together, a reactivation of the column failed, likely due to magnesium surface passivation. The separation of $\mathrm{Mg} / \mathrm{LiCl}$ allowed to reuse the column several times with different substrates. Nevertheless, we do not recommend its reutilization. For optimal results, 2 equivalents of $\mathrm{Mg}^{*}$ (chips/powder, 1:1) and 2 equivalents of $\mathrm{LiCl}$ must be used at a single time. 
System scope: The bicomponent column was employed to obtain the turbo Grignard reagent [45] as well as sec- and $n$-butylmagnesium chloride-lithium chloride complexes as THF solutions $(\approx 10 \mathrm{~mL})$. Very good yields were obtained: iPrMgCl-LiCl $2.19 \mathrm{M}(88 \%) ; s-\mathrm{BuMgCl} \cdot \mathrm{LiCl} 2.15 \mathrm{M}(86 \%)$, and $n$ - $\mathrm{BuMgCl} \cdot \mathrm{LiCl}(2.13 \mathrm{M}, 85 \%$, Table 2, entries 2-4).

The formation of the turbo Grignard reagent (iPrMgCl$\cdot \mathrm{LiCl}$ ) was scaled up to $\approx 100 \mathrm{mmol}$ using a $15 \times 100 \mathrm{~mm}$ column, and the results were compared with the Knochel batch protocol [58]. Using our flow procedure, the generation of a higher iPrMgCl$\cdot \mathrm{LiCl}$ concentration $(2.10 \mathrm{M}$ instead of $0.89 \mathrm{M})$ in a shorter reaction time $(1.5 \mathrm{~h}$ instead of $12 \mathrm{~h}$ ) caused a 7 -fold throughput and a 15-fold space-time yield improvement (Table 3).

Table 3: Comparison of the batch [58] and flow conditions for the synthesis of $\mathrm{PrMgCl} \cdot \mathrm{LiCl}$.

\begin{tabular}{lll} 
iPrMgCl·LiCl & batch & flow \\
\hline mmol of 2-chloropropane & 100 & 100 \\
[2-chloropropane] (M) & 0.92 & 2.50 \\
$t(\mathrm{~h})$ & 12 & 1.50 \\
[iPrMgCl·LiCl] (M) & 0.89 & $2.10^{\mathrm{a}}$ \\
conversion of 2-chloropropane (\%) & 100 & 100 \\
throughput (mmol·h & \\
normalized space-time yield $^{\mathrm{b}}$ & 7 & 50 \\
\end{tabular}

apropene and 2,3-dimethylbutane as side products. ${ }^{\text {b }}$ Space-time yield $\left(\mathrm{mmol} \cdot \mathrm{mL}^{-1} \cdot \mathrm{h}^{-1}\right)$ : batch: 0.065 , flow: 0.980 .

\section{Knochel-Hauser bases via stratified packed-bed columns containing magnesium and $\mathrm{LiCl}$}

Objective: To generate amidomagnesium lithium chloride complexes (Knochel-Hauser bases) from turbo Grignard formed in situ and the corresponding amine using stratified bicomponent packed-bed columns composed of magnesium metal and lithium chloride.
Challenges: Gas formation from amine deprotonation, residence time optimization due to variations in the amine and amide properties.

System setup: The same flow system was used as for the generation of turbo Grignard reagents (Figure S2, Supporting Information File 1). For TMPH, a coil $\left(V=10 \mathrm{~mL}\right.$, ID $\left.=0.03^{\prime \prime}\right)$ was added downstream to increase the residence time (Figure S3, Supporting Information File 1).

We synthesized amidomagnesium chloride-lithium chloride complexes $\left(\mathrm{R}_{2} \mathrm{NMgCl} \cdot \mathrm{LiCl}\right)$ by the in situ formation of turbo Grignard in the presence of the corresponding amine. The reactions were carried out by flowing $\mathrm{iPCl} /$ amine, $1: 1$ dissolved in THF/toluene, $1: 1$ at a $0.5 \mathrm{~mL} / \mathrm{min}$ flow rate and $80{ }^{\circ} \mathrm{C}$. Toluene was required to solubilize the magnesium amide species. During the process, propane was generated, but no overpressure was observed. The flammable gas was released after the $\mathrm{BPR}$, together with the $\mathrm{R}_{2} \mathrm{NMgCl} \cdot \mathrm{LiCl}$ solution, in the collection flask, away from a heat source.

System scope: Bis(trimethylsilyl)amine (HMDS), diphenylamine $\left(\mathrm{Ph}_{2} \mathrm{NH}\right)$, aniline $\left(\mathrm{PhNH}_{2}\right)$, and 2,2,6,6-tetramethylpiperidine (TMPH) were selected as substrates. $\mathrm{Ph}_{2} \mathrm{NH}, \mathrm{HMDS}$, and $\mathrm{PhNH}_{2}$ due to their lower $\mathrm{p} K_{\mathrm{a}}(25,30$, and 31 , respectively, in DMSO) [59] and TMPH due to its broad application in synthesis (Knochel-Hauser base, $\mathrm{p} K_{\mathrm{a}}=37$ in DMSO) [47,59-69]. Excellent yields were obtained: HMDSMgCl.LiCl $1.15 \mathrm{M}$ (98\%), $\mathrm{Ph}_{2} \mathrm{NMgCl} \cdot \mathrm{LiCl} 1.16 \mathrm{M}(97 \%)$, and $\mathrm{PhNHMgCl} \cdot \mathrm{LiCl}$ (1.15 M, 96\%, Table 4, entries 1-3).

For TMPH, a $10 \mathrm{~mL}$ coil (20 min residence time $t_{\mathrm{R}}$ ) was added due to the slower reaction rate, and the $\mathrm{iPCl}$ amount was optimized to 1.2 equivalents (Scheme 1). Even if the addition of a coil increased the residence time for the TMPMgCl$\cdot \mathrm{LiCl}$ synthesis up to $25 \mathrm{~min}$, our flow setup was 9 times faster than the batch version, which usually takes $24 \mathrm{~h}$ at room temperature $[47,67]$. The reaction was carried out by flowing $\mathrm{PrCl} / \mathrm{TMPH}$, 1.2:1 dissolved in THF/toluene, $1: 1$ at a $0.5 \mathrm{~mL} / \mathrm{min}$ flow rate and $80^{\circ} \mathrm{C}$.

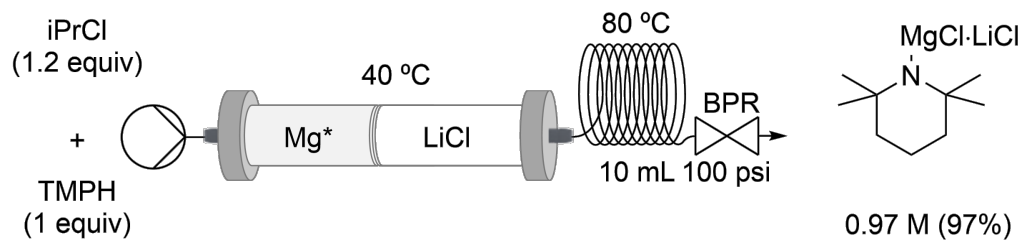


Table 4: Reaction between amines and isopropylmagnesium chloride generated in situ. Knochel-Hauser bases synthesis using a stratified packed-bed column of activated magnesium and lithium chloride. ${ }^{a}$

\begin{tabular}{|c|c|c|c|c|}
\hline & & $0^{\circ} \mathrm{C}$ & & \\
\hline $\begin{array}{c}+ \\
\mathrm{R}_{2} \mathrm{NH}\end{array}$ & $\mathrm{Mg}$ & $\mathrm{LiCl}$ & & $\mathrm{R}_{2} \mathrm{NMgCl} \cdot \mathrm{LiC}$ \\
\hline entry & $\mathrm{R}_{2} \mathrm{NH}$ & {$[\mathrm{RX}](\mathrm{M})$} & $\begin{array}{l}\text { [R2NMgX. } \\
\text { LiCL] (M) }\end{array}$ & yield (\%) \\
\hline 1 & HMDS & 1.2 & 1.17 & 98 \\
\hline 2 & $\mathrm{Ph}_{2} \mathrm{NH}$ & 1.2 & 1.16 & 97 \\
\hline 3 & $\mathrm{PhNH}_{2}$ & 1.2 & 1.15 & 96 \\
\hline
\end{tabular}

a 2 -chloropropane (1 equiv) and amine (1 equiv) THF/toluene, 1:1 solution $(1.2 \mathrm{M}, 30 \mathrm{~mL}$ ) was pumped at a $0.5 \mathrm{~mL} / \mathrm{min}$ flow rate and $80^{\circ} \mathrm{C}$ through a column (ID $=10 \mathrm{~mm}$ ) of activated $\mathrm{Mg}^{*}$ ( 2 equiv) chips/ powder, 1:1 and anhydrous $\mathrm{LiCl}$ (2 equiv) separated with fiberglass. ${ }^{b}$ Quantitative $\mathrm{RX}$ conversion. ${ }^{\mathrm{C}}$ Determined by the titration of an overall $\mathrm{R}_{2} \mathrm{MgCl} \cdot \mathrm{LiCl}$ solution $(\approx 25 \mathrm{~mL})$ collected in the steady state.

As a drawback, we observed $\mathrm{LiCl}$ precipitation in the flask $\approx 2 \mathrm{~h}$ after collection. A clear solution can be recovered by filtration through dried fiberglass using a cannula without a drastic concentration decrease. The same reaction was done in batch using turbo Grignard generated in flow, and the same result was observed, proving that $\mathrm{LiCl}$ is coming from $\mathrm{PrMgCl} \cdot \mathrm{LiCl}$. The analysis of the precipitate by NMR and GC-MS, after being washed with pentane at $0{ }^{\circ} \mathrm{C}$ and dried under vacuum, showed no evidence of organic compounds. It seemed that $\mathrm{TMPMgCl} \cdot \mathrm{LiCl}$ coordinated less $\mathrm{LiCl}$ than the corresponding iPrMgCl$\cdot \mathrm{LiCl}$ and triggered $\mathrm{LiCl}$ crystallization. To solve this issue, the packed-bed column temperature was decrease from $80{ }^{\circ} \mathrm{C}$ to $40{ }^{\circ} \mathrm{C}$ to reduce the amount of $\mathrm{LiCl}$ dissolved in the iPrMgCl$\cdot \mathrm{LiCl}$ solution. Under these conditions, we were able to obtain TMPMgCl$\cdot \mathrm{LiCl} 0.97 \mathrm{M}(97 \%)$ as a solution $(\approx 40 \mathrm{~mL})$ that remained clear for much longer (Scheme 1). We suggest to directly react the $\mathrm{TMPMgCl} \cdot \mathrm{LiCl}$ solution in flow or to telescope the reagent in batch with the next step. The Knochel-Hauser base was also scaled up to $\approx 100 \mathrm{mmol}$ using a $15 \mathrm{~mm}$ ID column. Using our flow procedure, a similar $\mathrm{TMPMgCl} \cdot \mathrm{LiCl}$ concentration $(\approx 1.0 \mathrm{M})$ compared to the Knochel protocol was obtained [47,67], but the reaction time was reduced from $36 \mathrm{~h}$ to $4 \mathrm{~h}$, providing a 10-fold increment in throughput and space-time yield (Table 5).
Table 5: Comparison between batch $[47,67]$ and flow conditions for the synthesis of (TMPMgCl-LiCl).

\begin{tabular}{lcc} 
TMPMgCl-LiCl & batch & flow \\
\hline mmol of 2-chloropropane & 100 & 100 \\
[2-chloropropane] (M) & 1.20 & 1.20 \\
[TMPH] (M) & 1.05 & 1.00 \\
$t(\mathrm{~h})$ & 36 & 4 \\
[TMPMgCl-LiCl] (M) & 1.03 & 0.97 \\
throughput $\left(\mathrm{mmol} \cdot \mathrm{h}^{-1}\right.$ ) & 2 & 22 \\
normalized space-time yield & 1 & 10 \\
\hline
\end{tabular}

aSpace-time yield $\left(\mathrm{mmol}^{\mathrm{mL}} \cdot \mathrm{mL}^{-1} \cdot \mathrm{h}^{-1}\right)$ : batch: 0.016 , flow: 0.160 .

We also found that $\mathrm{LiBr}$ could be used. The reaction was carried out under the same conditions. The high solubility of $\mathrm{LiBr}$ provided solutions that remained clear for days (TMPMgCl·LiBr $0.84 \mathrm{M}, 84 \%$, Scheme 2).

\section{Alkoxide bases via stratified packed-bed columns containing magnesium and $\mathrm{LiCl}$}

Objective: To generate magnesium alkoxide-lithium chloride complexes by telescoped reactions of turbo Grignards with tertamyl alcohol using stratified bicomponent packed-bed columns composed of magnesium metal and lithium chloride, a T-mixer, and a coil reactor.

Challenges: Alcohol incompatibility with the activating solution and alkoxide solubility.

System setup: The same flow system was used as for the generation of turbo Grignard reagents. Extra feed was added between the packed-bed column and the coil $(V=10 \mathrm{~mL}, \mathrm{ID}=$ 0.03 ") for the tert-amyl alcohol addition (Figure S4, Supporting Information File 1).

Finally, we explored the formation of sterically hindered oxygen bases by a direct alcohol deprotonation. Knochel-type tert-amyl magnesium alkoxide $(t$-AmylOMgCl$\cdot \mathrm{LiCl}) 1.0 \mathrm{M}$ $(95 \%)$ was obtained $(\approx 15 \mathrm{~mL})$ by the reaction of the corresponding alcohol (1.0 equiv) and turbo Grignard (1.2 equiv)

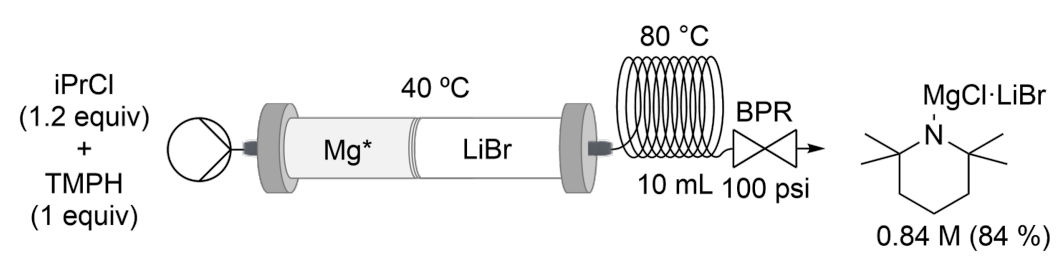

Scheme 2: Continuous flow synthesis of $\mathrm{TMPMgCl} \cdot \mathrm{LiBr}$ with a stratified packed-bed column of activated magnesium and lithium bromide. 


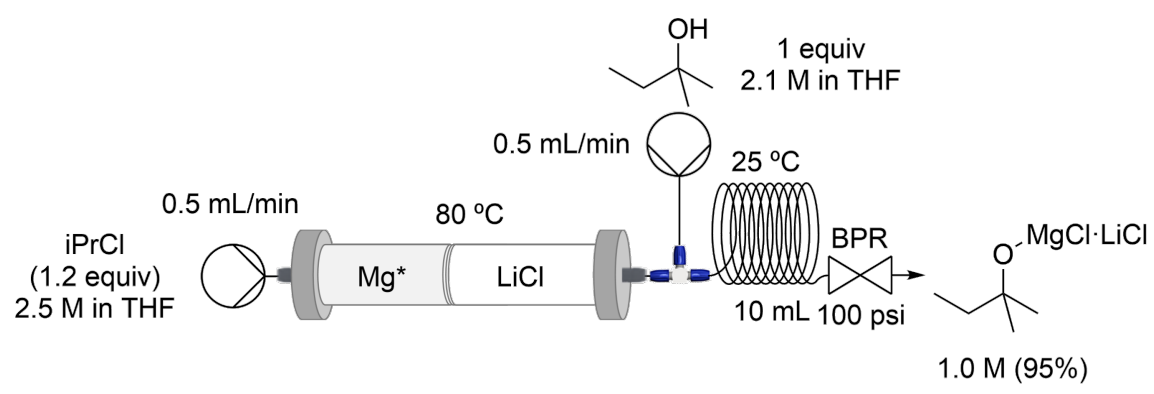

Scheme 3: Continuous flow synthesis of $t$-AmylOMgCl-LiCl with a stratified packed-bed column of activated magnesium and lithium chloride.

under flow conditions at $25{ }^{\circ} \mathrm{C}$ (Scheme 3). For $t$-AmylOMgCl$\cdot \mathrm{LiCl}$, the concentration was determined using a mixture of benzoic acid and thymolphthalein as an indicator [70].

\section{On-demand reagent proof of concept}

Objective: To reiterate the turbo Grignard and Knochel-Hauser base synthesis on the ODR prototype.

Challenges: The changes in the reactor material from reusable glass to disposable perfluorinated columns and the modification in the bicomponent $(\mathrm{Mg} / \mathrm{LiCl})$ configuration from a single stratified column to two separated monocomponent columns.

System setup: The internal diameter of the perfluorinated tubular reactor used on the ODR prototype was limited to 6.3 $\mathrm{mm}$ to maintain an efficient heat transfer. Due to this ID limitation and the heater dimensions, we decided to separate $\mathrm{Mg}$ and $\mathrm{LiCl}$ in two tubular reactors.

First, the concentration stability in the steady state and the scalability up to $\approx 100 \mathrm{mmol}$ was verified using two perfluorinated tubular reactors of $9.5 \mathrm{~mm}$ (ID) on the Vapourtec flow system. The first column containing $\mathrm{Mg}$ was heated at $80{ }^{\circ} \mathrm{C}$, using a temperature-controlled glass manifold [51]. The $\mathrm{LiCl}$ column was kept at $25{ }^{\circ} \mathrm{C}$. The concentration was followed over time during the conversion of 2-chloropropane in THF (56 mL, 2.2 $\mathrm{M})$ into iPrMgCl$\cdot \mathrm{LiCl}(50 \mathrm{~mL}, 1.91 \mathrm{M}$, Figure 6). Ten samples of $5 \mathrm{~mL}$ were collected, and the concentration was determined in duplicates using 2-hydroxybenzaldehyde phenylhydrazone.

The results demonstrated a continuous and stable generation of iPrMgCl$\cdot \mathrm{LiCl}(\approx 100 \mathrm{mmol})$ in the steady state under similar ODR prototype conditions. A certain volume of the starting material solution $(6 \mathrm{~mL})$ was discarded to prevent the dilution of iPrMgCl$\cdot \mathrm{LiCl}$ at the beginning and at the end of the experiment due to solvent diffusion. We stipulate that these results illustrate that our system provides a high-quality material for the discovery-scale needs. This approach is not suitable for a large scale and is not designed to be scaled. The goal is to aid discovery efforts to increase the reagent reliability.

The synthesis of $\approx 10 \mathrm{~mL}$ turbo Grignard, iPrMgCl$\cdot \mathrm{LiCl}$, and $\approx 10 \mathrm{~mL}$ of the Knochel-Hauser base derived from HMDS, $\mathrm{HMDSMgCl} \cdot \mathrm{LiCl}$, was reiterated on the ODR prototype. Similarly, an iPrMgCl$\cdot \mathrm{LiCl}$ yield of $86 \%$ was obtained (Scheme 4) using the optimized conditions established on a commercial flow system with a single reusable bicomponent glass column (Table 2, entry 2) and with two separated disposable monocomponent columns (Figure 6). The cartridge is composed of three solution bags (THF, the activating solution, and the $\mathrm{iPrCl}$ solution) and two tubular reactors ( $\mathrm{Mg}$ chips/powder and $\mathrm{LiCl}$ ) connected in-series (Figure S5, Supporting Information File 1).

For $\mathrm{HMDSMgCl} \cdot \mathrm{LiCl}$, the same cartridge configuration was used (Figure S5, Supporting Information File 1), and a slightly lower yield (83\%) was obtained (Scheme 5) compared to the reaction done on the Vapourtec flow system (Table 4, entry 1).

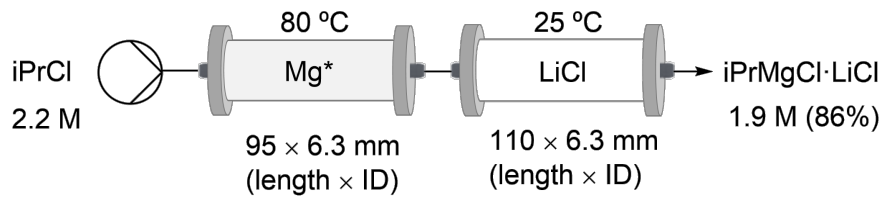

Scheme 4: Synthesis of $\mathrm{PrMgCl} \cdot \mathrm{LiCl}$ on the ODR prototype. 


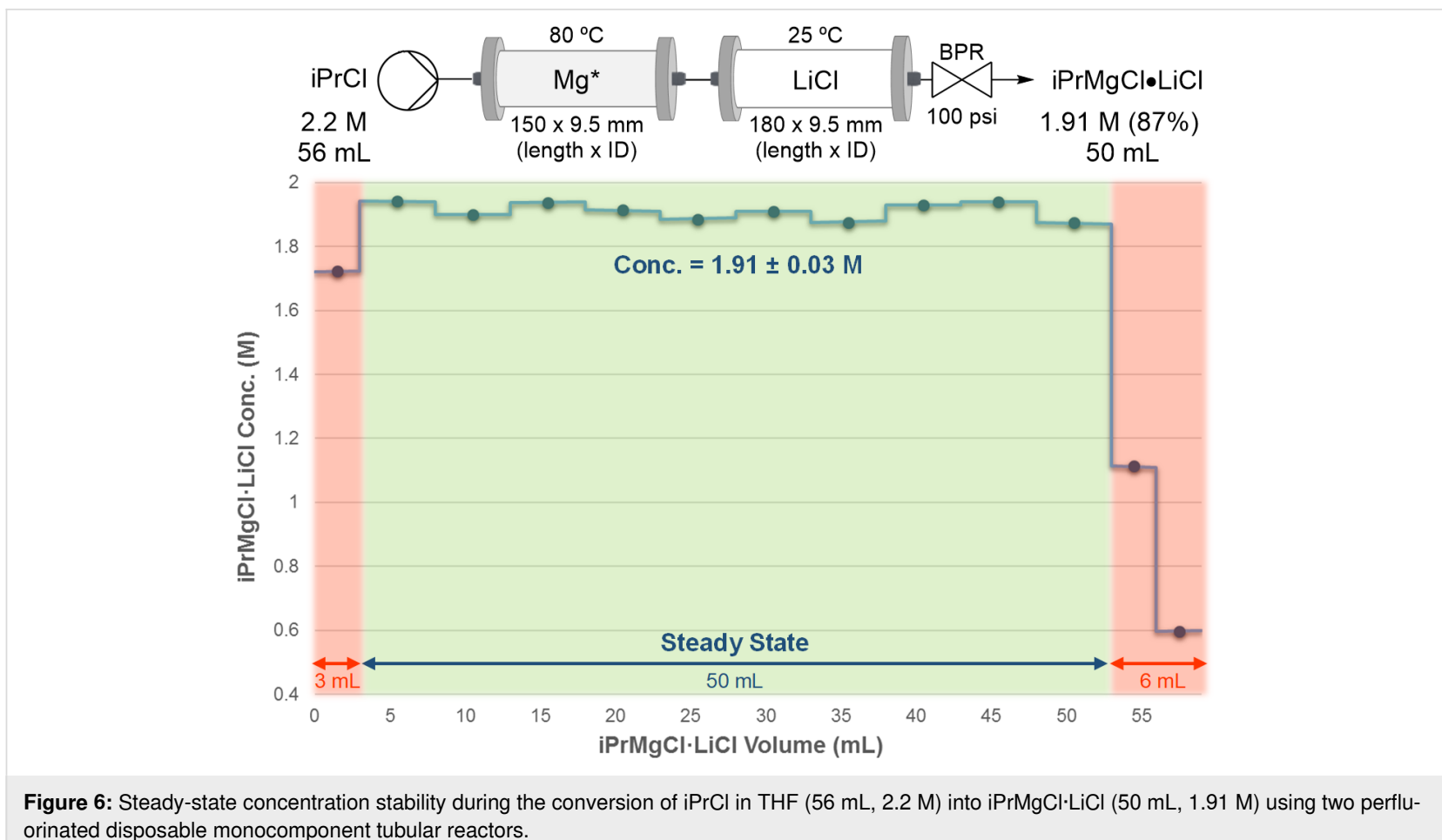

Figure 6: Steady-state concentration stability during the conversion of $\mathrm{iPrCl}$ in THF ( $56 \mathrm{~mL}, 2.2 \mathrm{M})$ into iPrMgCl$\cdot \mathrm{LiCl}(50 \mathrm{~mL}, 1.91 \mathrm{M})$ using two perfluorinated disposable monocomponent tubular reactors.

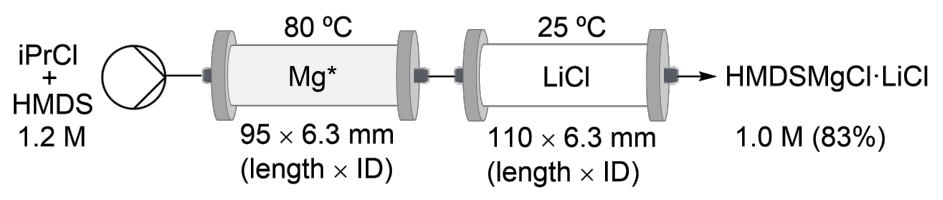

Scheme 5: Synthesis of HMDSMgCl-LiCl on the ODR prototype.

This variation was attribute to the unsteady flow rate produced by propane released during the reaction, and thus affecting the fluid dynamics and the back-pressure control.

The product purities, a quantitative $\mathrm{iPCl}$ conversion, and the yields were confirmed by NMR (Section 5, Supporting Information File 1), demonstrating the ODR prototype ability to safely produce high-quality organomagnesium reagents on demand.

\section{Conclusion}

We have developed a new flow setup for the on-demand synthesis of highly concentrated $(\approx 2 \mathrm{M})$ turbo Grignards from alkyl chlorides using a stratified packed-bed column of activated magnesium and lithium chloride. The volumes we can produce reliably are suitable for the target discovery scale audience. The magnesium activation in a packed-bed column is safer and faster in comparison to batch protocols. $\mathrm{LiCl}$ enhances the solubility and reactivity of organomagnesium compounds, and our moisture-free setup makes it possible to directly use the hygroscopic $\mathrm{LiCl}$ in a solid form. The back-pressure control allows a high-temperature oxidative addition reaction and enables the quantitative conversion of less reactive but more cost-effective alkyl chlorides. Furthermore, a low-cost pod-style synthesizer prototype has been designed and built. The reagents were prepacked in disposable perfluorinated assemblies-bags, cartridges, and tubings-sealed together using a new thermal bonding method. This on-demand concept was demonstrated by preparing the turbo Grignard reagent and the Knochel-Hauser base (optimized on a commercial flow system). We predict that with small modifications, this system could be configured to produce many different reagents. Our group is currently working on an organolithium version of this on-demand reagent approach.

\section{Experimental}

Turbo Grignard: isopropylmagnesium chloride-lithium chloride complex (iPrMgCl-LiCl): 2-Chloropropane (2.975 g, 
$3.46 \mathrm{~mL}, 37.5 \mathrm{mmol}, 1$ equiv) was dissolved in THF (11.5 mL) in a flask under argon. A $2.5 \mathrm{M}$ organic-halide solution was flowed through a column (ID $=10 \mathrm{~mm}$, length $=100 \mathrm{~mm}$ ) of activated magnesium (chips/powder, 1:1, w/w, $1.86 \mathrm{~g}, 75 \mathrm{mmol}$, 2 equiv) and anhydrous lithium chloride $(3.21 \mathrm{~g}, 75 \mathrm{mmol}$, 2 equiv), with a BPR (100 psi) at a $0.5 \mathrm{~mL} / \mathrm{min}$ flow rate and at $80{ }^{\circ} \mathrm{C}$. After $\approx 4 \mathrm{~min}$, the outcome solution was collected in a vial under an inert atmosphere containing 2-hydroxybenzaldehyde phenylhydrazone (20-40 mg). When the yellow-colored solution turned orange, the turbo Grignard reagent was collected in a flask under argon. When the starting material solution ran out, the organomagnesium collection was maintained for 4 min ( $\approx 2$-fold the residence time), flowing THF at $0.5 \mathrm{~mL} / \mathrm{min}$, yielding $88 \%$ of the isopropylmagnesium chloride-lithium chloride complex as clear 2.19 M solution $(\approx 10 \mathrm{~mL})$.

Knochel-Hauser base: lithium dichloro(2,2,6,6-tetramethylpiperidinato)magnesate (TMPMgCl-LiCl): 2-Chloropropane $(4.284 \mathrm{mg}, 4.99 \mathrm{~mL}, 54.0 \mathrm{mmol}, 1.2$ equiv) and 2,2,6,6-tetramethylpiperidine (TMPH, $6.420 \mathrm{~g}, 7.67 \mathrm{~mL}$, $45.0 \mathrm{mmol}, 1.0$ equiv) were dissolved in THF $(16.2 \mathrm{~mL})$ and toluene $(16.2 \mathrm{~mL})$ in a flask under argon. The mixed solution of the organic halide $(1.2 \mathrm{M})$ and the amine was flowed through a column (ID $=10 \mathrm{~mm}$, length $=100 \mathrm{~mm}$ ) of activated magnesium (chips/powder, 1:1, w/w, $2.23 \mathrm{~g}, 90 \mathrm{mmol}, 2$ equiv) and lithium chloride ( $3.85 \mathrm{~g}, 90 \mathrm{mmol}, 2$ equiv) at $0.5 \mathrm{~mL} / \mathrm{min}$, $40{ }^{\circ} \mathrm{C}$, and atmospheric back pressure. After $\approx 4 \mathrm{~min}$, the outcome solution was collected in a vial under an inert atmosphere containing 2-hydroxybenzaldehyde phenylhydrazone (20-40 mg). When the yellow-colored solution turned orange, the mixture was flowed through the coil at $0.5 \mathrm{~mL} / \mathrm{min}, 80^{\circ} \mathrm{C}$, and 100 psi back pressure. When the starting material solution ran out, THF/toluene, 1:1 was pumped at $0.5 \mathrm{~mL} / \mathrm{min}$ to maintain the mixture flowing. After $\approx 20 \mathrm{~min}$, the gas released was observed, and the outcome solution was collected in a vial under an inert atmosphere containing 2-hydroxybenzaldehyde phenylhydrazone (20-40 mg). When the yellow-colored solution turned orange, the Knochel-Hauser base (TMPMgCl$\cdot \mathrm{LiCl}$ ) solution was collected in a flask under argon. The organomagnesium collection was maintained for $20 \mathrm{~min}$ or until the gas release started to decrease, yielding $97 \%$ of the 2,2,6,6-tetramethylpiperidinylmagnesium chloride-lithium chloride complex (TMPMgCl$\cdot \mathrm{LiCl}$ ) solution as clear $0.97 \mathrm{M}$ solution $(\approx 40 \mathrm{~mL})$.

Knochel-type magnesium alkoxide (tert-amylOMgCl$\cdot \mathbf{L i C l})$ : 2-Chloropropane (1.983 g, $2.31 \mathrm{~mL}, 25.0 \mathrm{mmol}, 1.2$ equiv) was dissolved in THF $(7.7 \mathrm{~mL})$ in a flask under argon. 2-Methyl-2butanol (1.87 g, $2.32 \mathrm{~mL}, 21.0 \mathrm{mmol}, 1.0$ equiv) was dissolved in THF $(7.7 \mathrm{~mL})$ in a second flask under argon. The $2.5 \mathrm{M}$ organic-halide solution was flowed through a column (ID = $10 \mathrm{~mm}$, length $=100 \mathrm{~mm}$ ) of activated magnesium (chips/ powder, 1:1, w/w, $1.49 \mathrm{~g}, 60 \mathrm{mmol}, 2.4$ equiv) and lithium chloride $\left(2.57 \mathrm{~g}, 60 \mathrm{mmol}, 2.4\right.$ equiv) at $0.5 \mathrm{~mL} / \mathrm{min}, 80{ }^{\circ} \mathrm{C}$, and 100 psi back pressure. After $\approx 4$ min, the outcome solution was collected in a vial under an inert atmosphere.

\section{Supporting Information}

All details for the flow procedures and reactors assembly (full part list, flow system photos, and ODR prototype protocols) and all experimental data of the chemical reactions (optimization, packed-bed particle size study, and concentration determination) and NMR spectra.

\section{Supporting Information File 1}

Additional experimental data.

[https://www.beilstein-journals.org/bjoc/content/ supplementary/1860-5397-16-115-S1.pdf]

\section{Acknowledgements}

We thank Bernat Moreno (https://www.marroiak.com/) for his artwork of Figure 1 comparing on-demand coffee and turbo Grignard pod-style machines.

\section{Funding}

We thank the DARPA for financial support (Army W31P4Q18-1-0001).

\section{ORCID ${ }^{\circledR}$ iDs}

Mateo Berton - https://orcid.org/0000-0002-9983-3656

\section{Preprint}

A non-peer-reviewed version of this article has been previously published as a preprint doi:10.3762/bxiv.2020.40.v1

\section{References}

1. Movsisyan, M.; Delbeke, E. I. P.; Berton, J. K. E. T.; Battilocchio, C.; Ley, S. V.; Stevens, C. V. Chem. Soc. Rev. 2016, 45, 4892-4928. doi:10.1039/c5cs00902b

2. Gutmann, B.; Kappe, C. O. J. Flow Chem. 2017, 7, 65-71. doi:10.1556/1846.2017.00009

3. Tsukanov, S. V.; Johnson, M. D.; May, S. A.; Kolis, S. P.; Yates, M. H.; Johnston, J. N. Org. Process Res. Dev. 2018, 22, 971-977. doi:10.1021/acs.oprd.8b00113

4. Murray, P. R. D.; Browne, D. L.; Pastre, J. C.; Butters, C.; Guthrie, D.; Ley, S. V. Org. Process Res. Dev. 2013, 17, 1192-1208. doi:10.1021/op4001548

5. Yoshida, J.-i.; Nagaki, A.; Yamada, T. Chem. - Eur. J. 2008, 14, 7450-7459. doi:10.1002/chem.200800582 
6. Nagaki, A.; Yoshida, J.-I. Preparation and Use of Organolithium and Organomagnesium Species in Flow. In Topics in Organometallic Chemistry 57; Noël, T., Ed.; Springer International Publishing AG: Cham, Switzerland, 2015; pp 137-176. doi:10.1007/3418_2015_154

7. Razzaq, T.; Kappe, C. O. Chem. - Asian J. 2010, NA. doi:10.1002/asia.201000010

8. Kupracz, L.; Kirschning, A. Adv. Synth. Catal. 2013, 355, 3375-3380. doi:10.1002/adsc.201300614

9. Adamo, A.; Beingessner, R. L.; Behnam, M.; Chen, J.; Jamison, T. F.; Jensen, K. F.; Monbaliu, J.-C. M.; Myerson, A. S.; Revalor, E. M.; Snead, D. R.; Stelzer, T.; Weeranoppanant, N.; Wong, S. Y.; Zhang, P. Science 2016, 352, 61-67. doi:10.1126/science.aaf1337

10. Zhang, P.; Weeranoppanant, N.; Thomas, D. A.; Tahara, K.; Stelzer, T.; Russell, M. G.; O'Mahony, M.; Myerson, A. S.; Lin, H.; Kelly, L. P.; Jensen, K. F.; Jamison, T. F.; Dai, C.; Cui, Y.; Briggs, N.; Beingessner, R. L.; Adamo, A. Chem. - Eur. J. 2018, 24, 2776-2784 doi:10.1002/chem.201706004

11. Bédard, A.-C.; Adamo, A.; Aroh, K. C.; Russell, M. G.; Bedermann, A. A.; Torosian, J.; Yue, B.; Jensen, K. F.; Jamison, T. F. Science 2018, 361, 1220-1225. doi:10.1126/science.aat0650

12. Jiang, T.; Bordi, S.; McMillan, A. E.; Chen, K.-Y.; Saito, F.; Nichols, P.; Wanner, B.; Bode, J. ChemRxiv 2019, Preprint. doi:10.26434/chemrxiv.7882799.v1

13. Opalka, S. M.; Park, J. K.; Longstreet, A. R.; McQuade, D. T. Org. Lett. 2013, 15, 996-999. doi:10.1021/ol303442m

14. Opalka, S. M.; Longstreet, A. R.; McQuade, D. T. Beilstein J. Org. Chem. 2011, 7, 1671-1679. doi:10.3762/bjoc.7.197

15. Alonso, N.; Miller, L. Z.; de M. Muñoz, J.; Alcázar, J.; McQuade, D. T. Adv. Synth. Catal. 2014, 356, 3737-3741. doi:10.1002/adsc.201400243

16. Miller, L. Z.; Hrudka, J. J.; Naro, Y. R.; Haaf, M.; Shatruk, M.; McQuade, D. T. J. Flow Chem. 2015, 5, 139-141. doi:10.1556/jfc-d-14-00039

17. Gilmore, K.; Vukelić, S.; McQuade, D. T.; Koksch, B.; Seeberger, P. H. Org. Process Res. Dev. 2014, 18, 1771-1776. doi:10.1021/op500310s

18. Dragulescu-Andrasi, A.; Miller, L. Z.; Chen, B.; McQuade, D. T.; Shatruk, M. Angew. Chem., Int. Ed. 2016, 55, 3904-3908. doi:10.1002/anie.201511186

19. Ley, S. V.; Fitzpatrick, D. E.; Ingham, R. J.; Myers, R. M. Angew. Chem., Int. Ed. 2015, 54, 3449-3464. doi:10.1002/anie.201410744

20. Li, J.; Ballmer, S. G.; Gillis, E. P.; Fujii, S.; Schmidt, M. J.; Palazzolo, A. M. E.; Lehmann, J. W.; Morehouse, G. F.; Burke, M. D. Science 2015, 347, 1221-1226. doi:10.1126/science.aaa5414

21. Seeberger, P. H. Acc. Chem. Res. 2015, 48, 1450-1463. doi:10.1021/ar5004362

22. Fitzpatrick, D. E.; Ley, S. V. React. Chem. Eng. 2016, 1, 629-635. doi:10.1039/c6re00160b

23. Sans, V.; Cronin, L. Chem. Soc. Rev. 2016, 45, 2032-2043. doi:10.1039/c5cs00793c

24. Dragone, V.; Sans, V.; Henson, A. B.; Granda, J. M.; Cronin, L. Nat. Commun. 2017, 8, 15733-15740. doi:10.1038/ncomms15733

25. Fitzpatrick, D. E.; Ley, S. V. Tetrahedron 2018, 74, 3087-3100. doi:10.1016/j.tet.2017.08.050

26. Granda, J. M.; Donina, L.; Dragone, V.; Long, D.-L.; Cronin, L. Nature 2018, 559, 377-381. doi:10.1038/s41586-018-0307-8

27. Perera, D.; Tucker, J. W.; Brahmbhatt, S.; Helal, C. J.; Chong, A.; Farrell, W.; Richardson, P.; Sach, N. W. Science 2018, 359, 429-434. doi:10.1126/science.aap9112
28. Guberman, M.; Seeberger, P. H. J. Am. Chem. Soc. 2019, 141, 5581-5592. doi:10.1021/jacs.9b00638

29. Trobe, M.; Burke, M. D. Angew. Chem., Int. Ed. 2018, 57, 4192-4214. doi:10.1002/anie.201710482

30. Steiner, S.; Wolf, J.; Glatzel, S.; Andreou, A.; Granda, J. M.; Keenan, G.; Hinkley, T.; Aragon-Camarasa, G.; Kitson, P. J.; Angelone, D.; Cronin, L. Science 2019, 363, eaav2211. doi:10.1126/science.aav2211

31. Baker, K. V.; Brown, J. M.; Hughes, N.; Skarnulis, A. J.; Sexton, A. J. Org. Chem. 1991, 56, 698-703. doi:10.1021/jo00002a039

32. Bao, R. L. Y.; Zhao, R.; Shi, L. Chem. Commun. 2015, 51, 6884-6900. doi:10.1039/c4cc10194d

33. Ruppert, J. F.; White, J. D. J. Org. Chem. 1974, 39, 269-270. doi:10.1021/jo00916a043

34. Lau, S.-H.; Bourne, S. L.; Martin, B.; Schenkel, B.; Penn, G.; Ley, S. V. Org. Lett. 2015, 17, 5436-5439. doi:10.1021/acs.orglett.5b02806

35. Berton, M.; Huck, L.; Alcázar, J. Nat. Protoc. 2018, 13, 324-334. doi:10.1038/nprot.2017.141

36. Grachev, A. A.; Klochkov, A. O.; Shiryaev, V. I. Russ. J. Appl. Chem. 2012, 85, 629-638. doi:10.1134/s1070427212040167

37. Storozhenko, P. A.; Grachev, A. A.; Klochkov, A. O.; Shiryaev, V. I. Russ. J. Appl. Chem. 2013, 86, 387-393. doi:10.1134/s1070427213030166

38. Goldbach, M.; Danieli, E.; Perlo, J.; Kaptein, B.; Litvinov, V. M.; Blümich, B.; Casanova, F.; Duchateau, A. L. L. Tetrahedron Lett. 2016, 57, 122-125. doi:10.1016/j.tetlet.2015.11.077

39. Kopach, M. E.; Cole, K. P.; Pollock, P. M.; Johnson, M. D.; Braden, T. M.; Webster, L. P.; Groh, J. M.; McFarland, A. D.; Schafer, J. P.; Adler, J. J.; Rosemeyer, M. Org. Process Res. Dev. 2016, 20, 1581-1592. doi:10.1021/acs.oprd.6b00131

40. Huck, L.; de la Hoz, A.; Díaz-Ortiz, A.; Alcázar, J. Org. Lett. 2017, 19, 3747-3750. doi:10.1021/acs.orglett.7b01590

41. Herath, A.; Molteni, V.; Pan, S.; Loren, J. Org. Lett. 2018, 20, 7429-7432. doi:10.1021/acs.orglett.8b03156

42. Menges-Flanagan, G.; Deitmann, E.; Gössl, L.; Hofmann, C.; Löb, P. Org. Process Res. Dev. 2020, 24, 315-321. doi:10.1021/acs.oprd.9b00493

43. Ziegler, D. S.; Wei, B.; Knochel, P. Chem. - Eur. J. 2019, 25 , 2695-2703. doi:10.1002/chem.201803904

44. Klatt, T.; Markiewicz, J. T.; Sämann, C.; Knochel, P. J. Org. Chem. 2014, 79, 4253-4269. doi:10.1021/jo500297r

45. Gavryushin, A.; Knochel, P. Lithium Dichloro(1-methylethyl)-magnesate. Encyclopedia of Reagents for Organic Synthesis; John Wiley \& Sons: New York, 2010 doi:10.1002/047084289x.rn01161

46. Hauk, D.; Lang, S.; Murso, A. Org. Process Res. Dev. 2006, 10 , 733-738. doi:10.1021/op0600153

47. Krasovskiy, A.; Krasovskaya, V.; Knochel, P. Angew. Chem., Int. Ed. 2006, 45, 2958-2961. doi:10.1002/anie.200504024

48. García-Álvarez, P.; Graham, D. V.; Hevia, E.; Kennedy, A. R.; Klett, J.; Mulvey, R. E.; O'Hara, C. T.; Weatherstone, S. Angew. Chem., Int. Ed. 2008, 47, 8079-8081. doi:10.1002/anie.200802618

49. Kloetzing, R. J.; Krasovskiy, A.; Knochel, P. Chem. - Eur. J. 2007, 13, 215-227. doi:10.1002/chem.200600738

50. https://www.vapourtec.com/products/r-series-flow-chemistry-system-ov erview/ (accessed April 2, 2020).

51. (accessed April 2, 2020). https://www.dibaind.com/labware/\#omnifitsupsup-labware-glasschroma tography-columns (accessed Apr 02, 2020). 
52. Love, B. E.; Jones, E. G. J. Org. Chem. 1999, 64, 3755-3756. doi:10.1021/j0982433e

53. Blumberg, S.; Martin, S. F. Tetrahedron Lett. 2015, 56, 3674-3678. doi:10.1016/j.tetlet.2015.02.068

54. Krasovskiy, A.; Knochel, P. Synthesis 2006, 890-891. doi:10.1055/s-2006-926345

55. Hoye, T. R.; Eklov, B. M.; Voloshin, M. Org. Lett. 2004, 6, 2567-2570. doi:10.1021/ol049145r

56. Ashby, E. C.; Smith, M. B. J. Am. Chem. Soc. 1964, 86, 4363-4370. doi:10.1021/ja01074a026

57. Kadam, A.; Nguyen, M.; Kopach, M.; Richardson, P.; Gallou, F.; Wane, Z.-K.; Zhang, W. Green Chem. 2013, 15, 1880-1888. doi:10.1039/c3gc40702k

58. Krasovskiy, A.; Knochel, P. Angew. Chem., Int. Ed. 2004, 43, 3333-3336. doi:10.1002/anie.200454084

59. http://evans.rc.fas.harvard.edu/pdf/evans_pKa_table.pdf (accessed April 2, 2020)

60. Lin, W.; Baron, O.; Knochel, P. Org. Lett. 2006, 8, 5673-5676. doi:10.1021/ol0625536

61. Boudet, N.; Lachs, J. R.; Knochel, P. Org. Lett. 2007, 9, 5525-5528. doi:10.1021/ol702494k

62. Boudet, N.; Dubbaka, S. R.; Knochel, P. Org. Lett. 2008, 10, 1715-1718. doi:10.1021/ol800353s

63. Stoll, A. H.; Knochel, P. Org. Lett. 2008, 10, 113-116. doi:10.1021/ol7025872

64. Mosrin, M.; Knochel, P. Org. Lett. 2008, 10, 2497-2500. doi:10.1021/ol800790g

65. Balkenhohl, M.; Greiner, R.; Makarov, I. S.; Heinz, B.; Karaghiosoff, K.; Zipse, H.; Knochel, P. Chem. - Eur. J. 2017, 23, 13046-13050. doi:10.1002/chem.201703638

66. Balkenhohl, M.; Heinz, B.; Abegg, T.; Knochel, P. Org. Lett. 2018, 20 , 8057-8060. doi:10.1021/acs.orglett.8b03698

67. Göbel, D.; Clamor, N.; Nachtsheim, B. J. Org. Biomol. Chem. 2018, 16, 4071-4075. doi:10.1039/c8ob01072b

68. Balkenhohl, M.; Salgues, B.; Hirai, T.; Karaghiosoff, K.; Knochel, P. Org. Lett. 2018, 20, 3114-3118. doi:10.1021/acs.orglett.8b01204

69. Castelló-Micó, A.; Knochel, P. Synthesis 2018, 50, 155-169. doi:10.1055/s-0036-1590887

70. Bradley,, D. C. Metal-Organic Compounds. Advances in Chemistry; American Chemical Society: Washington, DC, 1959; pp 10-36. doi:10.1021/ba-1959-0023.ch002

Bradley, D. C. Metal Alkoxides. Metal-Organic Compounds. In Advances in Chemistry; American Chemical Society: Washington, DC, 1959; Vol. 23, pp 10-36. doi:10.1021/ba-1959-0023.ch002

\section{License and Terms}

This is an Open Access article under the terms of the Creative Commons Attribution License (http://creativecommons.org/licenses/by/4.0). Please note that the reuse, redistribution and reproduction in particular requires that the authors and source are credited.

The license is subject to the Beilstein Journal of Organic Chemistry terms and conditions: (https://www.beilstein-journals.org/bjoc)

The definitive version of this article is the electronic one which can be found at: doi:10.3762/bjoc.16.115 